\title{
Parâmetros críticos para o desenvolvimento de extratos secos vegetais padronizados obtidos por spray-drying: da pesquisa a realidade da produção
}

\author{
Critical parameters for the development of standardized dry herbal \\ extracts obtained by spray-drying: from research to manufacturing reality
}

Recebido em: 10/05/2020 Aceito em: $02 / 10 / 2020$
Deise Cristina Drummond Xavier Paes LOPES; Caroline da Silva PEREIRA; Caroline Vianna Velasco CASTILHO; Márcia PIETROLUONGO; Ana Paula dos Santos MATOS; Thiago Frances GUIMARÃES; Alessandra Lifsitch VIÇOSA Laboratório de Farmacotécnica Experimental - Farmanguinhos, Fiocruz. Rua Sizenando Nabuco, 100, Manguinhos, CEP 21041-000. Rio de Janeiro, RJ, Brasil.

E-mail: alessandra.vicosa@far.fiocruz.br

\section{ABSTRACT}

Atomization or spray drying process is a frequent operation for obtaining dry extracts from medicinal plants. However, during the preparation of these herbal pharmaceutical active ingredients, several factors can affect the quality of intermediate products. Based on scientific literature and Brazilian legislation on herbal medicines, experiences of research and development ( $\&$ \&) group from Fiocruz and brainstorming among team members, it designed a cause and effect diagram (Ishikawa Diagram). This work raises critical points in the production process of these herbal ingredients, indicating aspects of the spray-drying process by theoretical and practical sides that can affect the quality of herbal medicine. According to the discussion of each step described in the Ishikawa diagram to spray-dried extract preparation, it was possible to rationalize the production process of this intermediary with a focus on transforming it into an herbal product.

Keywords: critical parameters; dry herbal extracts; spray-drying process; herbal medicines

\section{RESUMO}

O processo de secagem por atomização ou spray-drying é uma das operações mais frequentes para a obtenção de extratos secos a partir de plantas medicinais. No entanto, durante o processo de preparação desses insumos farmacêuticos ativos (IFA) de origem vegetal, uma série de fatores podem afetar a qualidade desses produtos intermediários. Por meio de levantamento bibliográfico científico e da legislação brasileira sobre medicamentos fitoterápicos, vivências do grupo em pesquisa e desenvolvimento (P\&D) da Fiocruz e da realização de Brainstorming entre os integrantes da equipe, foi elaborado um diagrama 
de causa e efeito (Diagrama de Ishikawa). Tal pesquisa teve o objetivo de levantar pontos críticos no processo de produção desses IFA de origem vegetal, apontando aspectos do processo de spray-drying de ordem teórica e prática que poderiam afetar a qualidade do produto fitoterápico. Com base nas informações mencionadas no diagrama e na discussão desses pontos acerca de cada etapa até a preparação do extrato seco, foi possível racionalizar o processo de obtenção desse intermediário, com foco em transformá-lo em produto fitoterápico.

Palavras-chave: parâmetros críticos; extratos secos vegetais; spray-drying; fitoterápicos

\section{INTRODUÇÃO}

A transformação de plantas medicinais em medicamentos fitoterápicos resulta em produtos de maior valor agregado, onde a matéria-prima para esses produtos é constituída, majoritariamente, por extratos secos. A secagem de extratos fluidos por atomização ou spray-drying é uma das técnicas mais utilizadas, por originar produtos de maior estabilidade química, físico-química e microbiológica (1). Além disso, os extratos secos permitem uma maior concentração dos princípios ativos a custo reduzido, bem como fácil logística e, ainda, representam uma alternativa para evitar a deterioração ou perda de substâncias químicas e garantem a estabilidade do material $(2,3)$.

Apesar das inúmeras vantagens, a tecnologia farmacêutica de preparação desses extratos secos, atualmente chamados de insumos farmacêuticos ativos (IFA) de origem vegetal, permeia uma gama de processos que necessitam ser bem conhecidos, estabelecidos e padronizados, pois geram produtos intermediários que irão exercer uma ação sobre uma próxima etapa de industrialização. $\mathrm{Na}$ busca pela otimização dos processos e garantia da qualidade dos produtos fitoterápicos, a legislação brasileira vem sendo atualizada e seguindo as exigências internacionais para desenvolvimento de produto contemplando todas as etapas do processo (4).

A Instrução Normativa (IN) 04/2014, da Agência Nacional de Vigilância Sanitária (Anvisa) - Guia de orientação para registro de Medicamento Fitoterápico e registro e notificação de Produto Tradicional Fitoterápico (5), descreve que a qualidade desses produtos deve ser assegurada com o controle de todas as etapas de sua produção, desde o processamento da droga vegetal até a obtenção do IFA de origem vegetal ou produto intermediário. A legislação brasileira relacionada à produção de medicamentos a partir de derivados de drogas vegetais, vem de encontro às normas internacionais como, por exemplo, a Conferência Internacional de Harmonização (do inglês, International Council for Harmonisation of Technical Requirements for Pharmaceuticals for Human Use - ICH), que publicou em novembro de 2009 o guia ICH Q8 (R2) (6). Este guia foi elaborado no intuito de contribuir para maior conhecimento e controle sobre os processos de fabricação de produtos farmacêuticos, utilizando uma nova abordagem denominada Quality by Design (QbD), ou Qualidade por concepção (QpC) (7). Entre as abordagens do QpC para o desenvolvimento de produtos, estão os parâmetros críticos de processo (gargalos tecnológicos), representados pelas variáveis de entrada, e as características de qualidade desejadas para o produto, como variáveis de saída. Devido ao grande número de variáveis que podem afetar a qualidade do produto, o uso de ferramentas gerenciais apresenta-se como vantagem para a racionalização do processo e consequente diminuição do número de experimentos (7).

A Farmacopeia Brasileira $6^{\mathrm{a}}$ edição (8) descreve métodos e critérios para o controle da qualidade de produtos farmacêuticos, inclusive aqueles de origem vegetal. Além disso, as regulamentações constantes no Consolidado de Normas de Registro e Notificação de Fitoterápicos (9) definem as diretrizes para o registro e boas práticas de fabricação de produtos e IFA de origem vegetal $(4,10,11)$. No entanto, existe uma escassez de trabalhos com enfoque industrial na literatura científica e poucas informações que auxiliem na identificação dos gar- 
galos tecnológicos no processo de fabricação desses produtos (12).

A produção do IFA de origem vegetal é uma etapa preliminar à produção de um medicamento fitoterápico. Esta etapa pode ser realizada em empresa distinta daquela que produz o fitoterápico (5). Outro ponto importante relacionado à obtenção desses IFA de origem vegetal é a padronização destes materiais. Geralmente, a padronização não é simples porque os materiais de origem vegetal apresentam diversas variáveis que os IFA de origem sintética não apresentam. Dentre as variáveis, destaca-se a variabilidade do material coletado (condições climáticas, tempo de cultivo, condições de crescimento da planta, época e horário da coleta) que impactam no perfil químico do material e, consequentemente, na atividade biológica (13, 14). Métodos analíticos ou substâncias químicas de referência nem sempre estão descritos ou disponíveis (13), precisando ser desenvolvidos ou isolados ainda na fase de pesquisa. Além disso, o estudo de estabilidade é recomendável e útil para melhor conhecimento das etapas de produção, armazenamento, estocagem e transporte ou manuseio desses IFA de origem vegetal, mesmo que ainda não seja exigido pela Anvisa (15).

A partir da expertise do grupo de pesquisa e desenvolvimento do Laboratório de Farmacotécnica Experimental (LabFE/Farmanguinhos-Fiocruz) e de levantamento bibliográfico, foi realizado um Brainstorming entre os componentes da equipe, onde foi construído um Diagrama de Causa e Efeito, no qual os pontos críticos no processo de secagem por spray drying foram levantados a fim de identificar os gargalos na tecnologia de obtenção de extratos secos vegetais. A abordagem focada na prática industrial é o diferencial deste trabalho que tenta trazer informações organizadas que facilitem o desenvolvimento destes extratos secos.

A técnica de Brainstorming, que significa tempestade de ideias, é realizada por meio da contribuição e motivação de todos os participantes envolvidos, onde surgem soluções para os problemas apresentados (16). O Diagrama de Causa e Efeito é uma ferramenta gráfica de análise de processo usada para representar fatores que influenciam um determinado problema e identifica possíveis áreas para melhorias no processo em questão $(6,17)$. No presente estudo, as causas seriam todas as etapas de processo que precedem a produção de extratos secos. O efeito seria a obtenção de um IFA de origem vegetal.

Este trabalho foi desenvolvido visando contribuir com a pesquisa e desenvolvimento de medicamentos fitoterápicos, de forma a apresentar os gargalos tecnológicos hoje existentes relativos à obtenção de extratos secos a partir da secagem por spray-drying desde sua pesquisa básica até sua inserção no ecossistema de produção de medicamentos fitoterápicos.

\section{MÉTODO}

Neste trabalho foi aplicada a técnica de Brainstorming e de construção de um diagrama de causas e efeitos como ferramentas da qualidade para a produção de um extrato seco vegetal (IFA) como intermediário na produção de medicamentos fitoterápicos.

O Brainstorming foi realizado pelo grupo de pesquisadores do Laboratório de Farmacotécnica Experimental (LabFE) de Farmanguinhos, Fiocruz, o qual tem como uma de suas responsabilidades, desenvolver produtos oriundos da pesquisa em produtos naturais. Nessa etapa, foram discutidos os aspectos críticos de processo para a produção desse intermediário, onde os inputs do diagrama foram os parâmetros do processo que poderiam afetar a qualidade do derivado vegetal produzido.

O diagrama de causas e efeitos foi construído colocando o efeito estudado dentro de um círculo do lado direito do diagrama, para onde apontava uma grande seta, vinda do lado esquerdo. Diretamente ligadas à principal seta traçada, foram delineadas ramificações, sob a forma de indicadores menores, que representaram as etapas do desenvolvimento tecnológico, como fatores principais que poderiam afetar o processo. Abaixo de cada ramo principal, foram listadas as possíveis causas relacionadas a cada etapa (18).

Para os processos produtivos, é comum utilizar alguns fatores principais genéricos chamados de $6 \mathrm{M}$, tais como: materiais, mão de obra, métodos de traba- 
lho, maquinaria, meio ambiente e medição, podendo ser modificados de acordo com cada caso (19).

Aspectos relacionados à estabilidade do IFA de origem vegetal apesar de não fazerem parte do processo de obtenção do mesmo, são importantes para fins de registro de produto fitoterápico $(10,12$, 20) e foram enumerados neste trabalho a partir da experiência em desenvolvimento tecnológico do grupo de pesquisa.

\section{RESULTADO E DISCUSSÃO}

A partir das informações obtidas do Brainstorming, foi construído um diagrama de causas e efeitos (Figura 1) e foram adotadas como causas, ou fatores principais, as seguintes etapas: processamento da droga vegetal, extração e concentração do extrato, a seleção do excipiente (agente de secagem) e a secagem do extrato.

Figura 1. Diagrama de causas e efeitos para obtenção de insumo farmacêutico ativo (IFA) de origem vegetal pelo método de atomização por spray-drying.

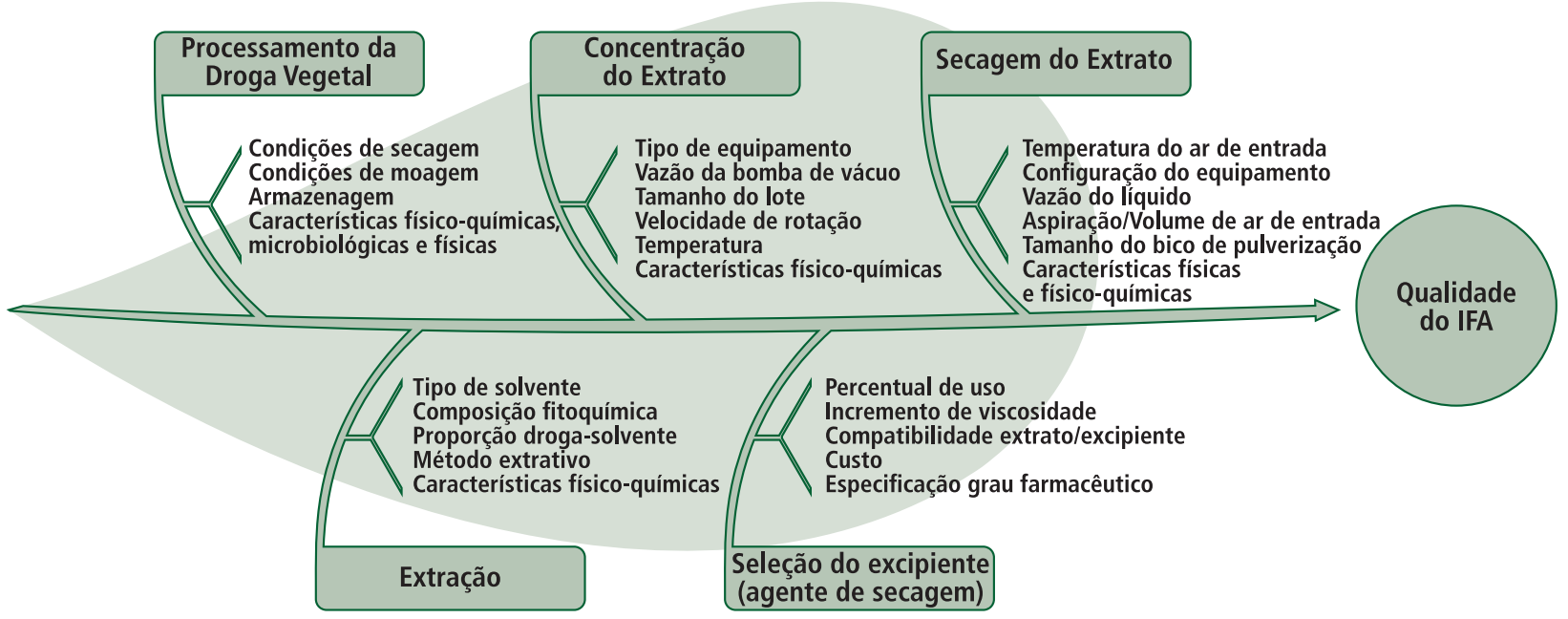

O processamento da droga vegetal se apresenta como primeiro ponto crítico no processo de obtenção de um IFA de origem vegetal (21). Dentre as causas mais importantes do processamento da droga vegetal, a padronização das características de secagem, moagem e armazenamento ocupam lugar de destaque. O processo de secagem deve ser avaliado com base em estudos sob diferentes condições de temperatura, tempo e carregamento do equipamento de secagem, de modo a viabilizar uma matéria-prima friável o suficiente para atender ao processo subsequente de moagem, bem como manter a estabilidade dos princípios ativos a partir de armazenagem em embalagem e local adequados. Além disso, esses processos apresentam impacto direto na umidade da droga vegetal (5) e podem ser monitorados utilizando o método descrito na monografia individual do produto na Farmacopeia Brasileira $6^{\text {a }}$ edição (8).

Para a determinação de água ao final da secagem da droga vegetal, podem ser utilizados o método de perda por dessecação (método gravimétrico), o método de Karl Fischer (método volumétrico) ou ainda o método de destilação azeotrópica $(8,22)$. Por se tratar de um ensaio prático e rápido, o método de perda por dessecação, utilizando analisador de umidade com lâmpada de infravermelho ou lâmpada halógena, é o mais utilizado.

O teor de água da droga vegetal pode estar relacionado diretamente com a possibilidade de crescimento microbiano (23), podendo inviabilizar seu uso para a produção de fitoterápicos. Na Farmacopeia Brasileira $6^{\mathrm{a}}$ edição, o teor máximo de água 
aceitável para drogas vegetais varia entre $6-15 \%$, exceto para aquelas cujas monografias indiquem outro valor (8).

Outro ensaio que pode ser utilizado para verificar a quantidade de água presente nas drogas vegetais é a análise de atividade de água (Aw). Esta análise permite avaliar a estabilidade física do material e prever o crescimento microbiano. De acordo com a Farmacopeia Brasileira $6^{\mathrm{a}}$ edição, a matéria-prima deve apresentar valores baixos de Aw, igual ou inferior a 0,75 (a $25^{\circ} \mathrm{C}$ ); valores de Aw maiores que 0,5 são considerados propícios para o crescimento microbiano no material analisado (24).

O controle microbiológico da matéria-prima vegetal pode ser destacado como um dos principais gargalos dessa etapa, inclusive deve-se estabelecer uma frequência mínima para ser realizado, com base em dados históricos dos testes de monitoramento microbiológico tanto ambiental quanto de equipamentos (25). É necessária previsão de possíveis gastos com irradiação da droga vegetal, para redução da carga microbiana, e possibilidade do uso do produto de forma segura $(8,25)$. A qualidade microbiológica de drogas vegetais e derivados pode ser atestada de acordo com limites estabelecidos na IN 04/2014 (5), na Farmacopeia Brasileira $6^{\text {a }}$ edição (8) e nas diretrizes da Organização Mundial da Saúde (OMS) para avaliação da qualidade dos fitoterápicos (26).

A determinação da umidade da droga vegetal também auxilia na escolha da proporção droga-solvente, pois drogas vegetais mais secas tendem a intumescer mais e consequentemente utilizar mais solventes. O índice de intumescimento da droga vegetal, embora não seja exigido pela legislação para registro de fitoterápico, é descrito na Farmacopeia Brasileira (8) e é imprescindível quando se trata de aumento de escala, previsão dos gastos com solventes, tamanhos de lotes e dimensionamento dos tanques de extração.

Além dos ensaios de contaminantes microbiológicos e teor de água, informações como o processo de moagem e o grau de cominuição da droga vegetal, são dados importantes que podem apresentar impacto no IFA. Dependendo das propriedades químicas dos constituintes de interesse na droga vegetal e do tipo de moinho utilizado, o aquecimento gerado nesse processo pode interferir na composição fitoquímica do material gerado, levando a perda de compostos voláteis ou termolábeis (27). Além disso, sabe-se da experiência prática que dependendo do grau de cominuição da droga pulverizada, pode haver maior superfície de contato com o solvente extrator ou não, impactando diretamente no rendimento da extração. A avaliação da distribuição granulométrica é um fator importante na preparação do extrato, pois dependendo da tenuidade do pó, e consequentemente de sua densidade, este tem maior ou menor contato com o solvente extrator, e a presença de partículas muito finas podem favorecer o entupimento dos filtros da etapa de filtração do extrato. A padronização do tamanho da partícula da droga vegetal pode ser definida através da utilização de moinhos e malhas de tamanhos conhecidos de maneira a possibilitar sua reprodutibilidade a lote a lote, onde a velocidade do moinho também deve ser padronizada para evitar alterações significativas deste parâmetro (8).

A segunda etapa do processo para obtenção do IFA de origem vegetal, que constitui um ponto crítico, é a extração da droga vegetal no que diz respeito aos solventes utilizados. Na maioria das vezes, o solvente orgânico utilizado na fase da pesquisa, e que se apresenta como a melhor opção para extração e aumento de rendimento de obtenção de princípios ativos, não se enquadra nas categorias permitidas quando se pensa em formular um produto para uso medicinal. Segundo a IN 04/2014 (5), exceto quando os solventes utilizados na obtenção do derivado forem álcool etílico ou água, resíduos de solventes devem ser determinados, pois os solventes residuais não são completamente removidos durante o processo de fabricação do IFA. Além disso, os solventes utilizados durante a etapa de pesquisa normalmente são de alta pureza, e podem encarecer o produto quando escalonados para a etapa de produção. Assim, os ensaios farmacológicos e analíticos devem ser validados para extratos obtidos com solventes grau técnico ou equivalentes, viabilizando assim um custo mais adequado ao produto final.

A Farmacopeia Brasileira $6^{\mathrm{a}}$ edição (8) traz uma descrição detalhada sobre a determinação de solventes residuais e sobre os limites aceitáveis em 
produtos farmacêuticos, visando sempre a segurança do paciente. Os solventes da classe 1 devem ser evitados, a menos que uma justificativa plausível seja apresentada considerando o risco-benefício da sua utilização. Os solventes de classe 2 têm seu uso limitado, enquanto os solventes de classe 3 são considerados os menos tóxicos e mais seguros para o paciente $(8,28)$.

Após a seleção do solvente a ser utilizado, a composição do extrato deve ser conhecida e padronizada. O perfil fitoquímico deve ser apresentado em laudo de estudos toxicológicos, pois impacta diretamente na determinação da atividade farmacológica, no desenvolvimento de etapas analíticas e na compatibilidade com adjuvantes tecnológicos $(5,27)$. A composição fitoquímica pode ser determinada por meio de diferentes técnicas analíticas como, por exemplo, cromatografia líquida de alta eficiência (CLAE), cromatografia de camada delgada (CCD), espectroscopia de infravermelho (IV), espectroscopia de Raman, dentre outras (14). Entretanto, para fins de controle da qualidade dos materiais vegetais, a escolha de uma única substância ou classe de substâncias predominante, que passa a ser chamada de marcador, é realizada para facilitar a quantificação e assegurar a qualidade do extrato obtido (5).

A escolha do marcador químico é predominantemente correlacionada com a atividade biológica do extrato, porém nem sempre esta relação ocorre, visto que a atividade biológica pode estar relacionada a efeito sinérgico de vários constituintes do extrato vegetal $(5,14)$.

Outro aspecto que deve ser previsto como ponto crítico na etapa de extração, é a proporção droga-solvente. Essa relação deve ser estimada ainda em escala laboratorial, pois além da importância com relação aos tamanhos de lotes e previsão de tamanhos de reatores ou tanques de extração, pode ser um fator para maior concentração de determinados metabólitos. Quanto menor a proporção droga-solvente, mais rapidamente ocorre a saturação do líquido extrator e com o aumento dessa escala, o solvente pode continuar carreando ativos para o leito da extração. Nesse momento, o cálculo do índice de intumescimento também deve ser utilizado de maneira a evitar a mudança na proporção entre droga e solvente quando há a transposição da escala laboratorial para a industrial.

Além da seletividade do solvente e da proporção utilizada com relação à droga vegetal, o método extrativo apresenta-se como gargalo na produção de IFA de origem vegetal quando se faz o aumento de escala. Os métodos mais comuns e utilizados em laboratório são a maceração dinâmica, a extração em aparelhagem de Soxhlet e a percolação. No entanto apresentam vantagens e desvantagens um em relação ao outro, e que devem ser avaliadas quando da escolha do método extrativo para uma determinada droga vegetal (8). Um exemplo disso é a presença de substâncias termolábeis que impossibilitaria a extração da droga em aparelhagem de Soxhlet, na qual a temperatura deve atingir no mínimo, a temperatura de ebulição do solvente. Mas, uma vez estabelecido o método extrativo em escala laboratorial, este deve ser preferencialmente mantido no aumento de escala e, portanto, deve ser avaliado o escalonamento dos tanques e adequações de espaço físico. A temperatura, bem como a agitação e tempo de extração também são fatores críticos que, quando modificados, podem alterar a constituição química do extrato. Esse conjunto de fatores deve ser padronizado desde a escala laboratorial para evitar mudanças de parâmetros, que poderão ter impacto direto na qualidade do produto intermediário (IFA de origem vegetal). A ferramenta de delineamento de experimentos tem sido muito utilizada nessa etapa para avaliar, por meio de métodos estatísticos, os melhores processos extrativos, condições e solventes extratores, através de testes conduzidos de forma planejada, com objetivo de obter um maior controle do processo realizando o mínimo de experimentos $(29,30)$. Além disso, o uso desta metodologia está totalmente alinhado ao guia Q8 (R2) do ICH relacionado ao desenvolvimento de produtos que recomenda o uso das técnicas de QpC (6).

Ainda na etapa extração, outro ponto crítico para o diagrama construído, são as caracterizações físico-químicas do extrato obtido. Nesse momento, o extrato segue as recomendações de caracterizações descritas na IN 04/2014 para extratos fluidos, como determinação de $\mathrm{pH}$, densidade, viscosidade podendo ser destacado o teor de resíduo seco como 
um dos fatores de impacto na etapa de concentração do extrato (5).

O terceiro ponto crítico do processo de obtenção do IFA de origem vegetal é a etapa de concentração do extrato, onde o primeiro aspecto a ser observado é o tipo de equipamento utilizado para essa retirada de solventes. Como na maioria dos casos, o evaporador rotativo é o equipamento mais utilizado em escala laboratorial para concentrar extratos, uma das preocupações é a capacidade do equipamento e a vazão da bomba de vácuo, dada normalmente em litros/hora. Esses fatores têm impacto direto no tempo estimado para a etapa de evaporação do extrato dependendo do tamanho do lote, o que faz com que parte do material a ser evaporado fique estocado por algum tempo. Essa estocagem por um longo período proporciona a precipitação de determinadas substâncias, principalmente quando é feita sob refrigeração, e pode fazer com que uma nova filtração no material seja realizada, alterando o teor de sólidos no meio. No caso de extratos aquosos o desafio é ainda maior, devido aos cuidados que se deve ter para a manutenção da qualidade microbiológica do mesmo. A velocidade de rotação do balão do evaporador rotativo e a temperatura do banho-maria, também devem ser controladas para evitar projeções de material com consequente contaminação do equipamento e evitar reações de degradação de substâncias ativas pelo aumento excessivo da temperatura.

$\mathrm{O}$ extrato concentrado deve manter as características físico-químicas adequadas e teor de sólidos que facilite o processo de secagem por spray dryer. A densidade e viscosidade do extrato devem ser compatíveis com o diâmetro do bico de aspersão do equipamento, para evitar o entupimento durante processo de secagem. Os valores ideais para os teores de sólidos dos extratos nessa etapa não se encontram na literatura e são determinados na experimentação. Porém, de forma a otimizar o custo do processo, o spray dryer deve operar com o máximo de teor de sólidos possível, ou seja, deve ser estimado uma faixa de percentual de sólidos no extrato concentrado. Da prática laboratorial, sabe-se que um mínimo de $25 \%$ é um valor aceitável que quando adicionado do adjuvante de secagem, dê como resultado um processo de bom rendimento e extratos secos estáveis dentro do preconizado pela
Farmacopeia Brasileira (8). Na indústria podem ser utilizados evaporadores de filme descendente (falling film), de circulação natural ou forçada, de placas, dentre outros $(31,32,33)$. Esses permitem operação de forma totalmente automática, mas em função de seus diferentes princípios de funcionamento, nova parametrização precisará sempre ser realizada.

A quarta etapa do processo que pode constituir um ponto crítico é a seleção do excipiente ou adjuvante de secagem. A utilização de adjuvantes é uma prática muito comum e é uma fase fundamental na etapa de secagem de extratos vegetais, pois podem determinar a estabilidade e a qualidade desses derivados, inclusive afetando suas características de biodisponibilidade (1). No processo de secagem são utilizados adjuvantes que além de facilitarem a secagem, melhoram as características do produto final e aumentam o rendimento do processo (34).

Os adjuvantes mais utilizados e citados na literatura são: dióxido de silício coloidal, amido de milho comum e modificado, ciclodextrinas, fosfato tricálcico, goma arábica, maltodextrina, celulose microcristalina e outros derivados de celulose (2, $34,35)$, e são adicionados ao extrato em torno de $10-30 \%$ sobre o teor de sólidos do extrato concentrado. Entretanto, alguns estudos mencionam a utilização de até $80 \%$ de adjuvante $(2,36)$, dependendo do teor de sólidos do extrato concentrado, do tipo de adjuvante escolhido e da composição do extrato.

Extratos que apresentam muitas substâncias com características graxas podem exigir maior percentual de adjuvantes de secagem. Porém, um percentual de uso abusivo terá um impacto no teor de substâncias biologicamente ativas, não sendo muito indicado, principalmente no caso de um fitoterápico de alta dose. $\mathrm{Na}$ busca da melhor performance de secagem, na qual a estabilidade e as características de processabilidade do pó estão inseridas, existe também a alternativa da combinação de diferentes tipos de agentes de secagem, onde um estudo de proporcionalidade entre eles e o extrato, é necessário. Dessa forma, estudos de desenho experimental são normalmente indicados para essa etapa bem como para o estudo das variáveis do equipamento por aspersão (37). 
Apesar da gama enorme de adjuvantes de secagem utilizados, devem ser estudadas a concentração de uso (esta concentração deve conferir uma adequada viscosidade após incorporação no extrato concentrado) e a compatibilidade dos mesmos com componentes presentes nos extratos. Um exemplo clássico de incompatibilidade ocorre entre derivados de celulose e gomas com taninos (38), assim esses excipientes não podem ser utilizados para secagem de extratos vegetais que contenham essa classe de metabólitos.

Por fim, dos gargalos levantados nessa etapa do processo, tanto o custo quanto a especificação do adjuvante devem ser analisados. Os adjuvantes do processo devem atender aos critérios de qualidade estabelecidos nas farmacopeias e a relação custo-benefício deve ser avaliada de modo a não encarecer demais o produto, mas também não deve afetar sua qualidade para fins da aplicação farmacêutica. Excipientes grau farmacêutico são recomendados.

A última etapa da cadeia da produção do extrato seco, mas que também pode apresentar gargalo é a atomização (secagem do extrato); etapa esta que deve ser otimizada de acordo com o equipamento utilizado, onde a temperatura de entrada é um dos parâmetros de maior importância sendo determinante na qualidade do produto obtido. Esta deve estar acima da temperatura de ebulição do solvente utilizado, o que não afeta o produto obtido, normalmente aspergido a uma temperatura de saída, em torno de $20 \%$ inferior da temperatura de entrada (1).

A escolha do solvente para o preparo do material para atomização determina o tipo de configuração do spray-dryer que precisa ser usado. $\mathrm{O}$ equipamento de spray-dryer pode funcionar em duas configurações: sistema aberto ou sistema fechado. O sistema aberto, que é o mais utilizado, é escolhido para atomizações de produtos dispersos ou solubilizados em meio aquoso. O sistema fechado é utilizado quando o material é preparado com solventes orgânicos. O sistema fechado previne explosão por conter um sistema acoplado de inertização do solvente e recuperação do mesmo $(39,40)$.

Como em outros processos farmacêuticos, o aumento de escala deve ser visto com cautela e, se possível, considerado no desenho inicial do desen- volvimento para não se tornar um entrave de difícil solução devido às limitadas opções de equipamentos para realização da escala piloto (etapa indispensável no processo). Os parâmetros de um spray dryer industrial são diferentes de um laboratorial, como por exemplo, capacidade de evaporação e rendimento, sendo necessário uma validação desses parâmetros no momento do escalonamento e alguns ajustes de processo. Essas diferenças dos equipamentos podem influenciar as propriedades de fluxo do material e características físico-químicas das partículas obtidas $(41,42)$.

No processo de atomização por spray-drying, diferentes parâmetros de processo, equipamento e formulação podem afetar a característica do produto atomizado. Dentre os parâmetros de processo que podem influenciar o produto atomizado destacam-se temperaturas de entrada e saída do ar, velocidade de alimentação, vazão do líquido, ou fluxo da bomba peristáltica, a vazão do ar de entrada ou aspiração $(1,40)$. Com relação aos parâmetros de equipamento, o tipo de fluxo de atomização ou tipo de bico atomizador e o formato do equipamento podem influenciar no produto final obtido. Já os parâmetros de formulação que influenciam a atomização são: a viscosidade, densidade, concentração de sólidos totais, tensão superficial e ponto de ebulição do solvente (40). A influência dos parâmetros no processo de secagem por atomização está mostrada no Quadro 1.

Após secagem do produto, caracterizações físicas e físico-químicas devem ser realizadas, no intuito de verificar as diferentes respostas que os diferentes parâmetros de secagem testados provocaram no produto final. Como caracterização física podem ser mencionadas as análises sensoriais, macroscópica por estereomicroscopia, e morfologia por microscopia ótica e eletrônica de varredura (MEV), onde são avaliadas a qualidade das partículas obtidas além da granulometria, e avaliações das propriedades dos pós como densidade, compressibilidade e propriedades de fluxo (43).

Para verificação da qualidade do extrato seco, análises de identificação e quantificação dos marcadores químicos, assim como teor de metabólitos ativos precisam ser realizadas por meio de técnicas cromatográficas (CCD e/ou CLAE) (27). Estes re- 
sultados devem estar de acordo com a dose prevista por ensaios farmacológicos e seguir metodologias descritas em compêndios oficiais (Farmacopeia Brasileira, Farmacopeia Americana, Farmacopeia Europeia, dentre outras) $(27,44)$. Além disso, a definição dos parâmetros de qualidade do extrato seco e dos procedimentos para obtenção deste material devem ser realizados a fim de garantir a padronização dos extratos (27).

Outras análises são realizadas a fim de avaliar a estabilidade do pó, como a higroscopia, onde o produto é exposto a diferentes umidades relativas por um período de tempo estabelecido, tendo seu valor determinado como grama ( $\mathrm{g}$ ) de umidade absorvida por $100 \mathrm{~g}$ de massa seca da amostra (45).O teor de resíduo seco também deve ser realizado e é preconizado pela Farmacopeia Brasileira devendo estar acima de 95\% (8). Estudos de Aw, adsorção e dessorção de água, embora não sejam farmacopeicos, também podem ser realizados como um estudo complementar e preditivo da higroscopia do produto (45).

$\mathrm{O}$ atendimento às necessidades de processo de todas as etapas levantadas como pontos críticos na preparação de um extrato seco, certamente irá proporcionar uma produção de um IFA de origem vegetal, no entanto para que esse intermediário seja padronizado (palavra esta que acaba tendo um valor de selo de qualidade), comercializado e transformado em um fitoterápico, outros requisitos são exigidos, como estudos de estabilidade.

Quadro 1. Parâmetros críticos relacionados à produção de extratos secos vegetais pelo processo de spray-drying.

\begin{tabular}{|c|c|}
\hline PARÂMETROS & EFEITOS \\
\hline \multicolumn{2}{|c|}{ Relacionados ao Processo } \\
\hline Temperatura de aquecimento do ar de secagem & $\begin{array}{l}\text { Determina a eficiência de secagem do material e o rendimento do } \\
\text { processo }\end{array}$ \\
\hline Vazão de bombeamento do material líquido & $\begin{array}{l}\text { Determina a eficiência de secagem do material e tamanho de partícula } \\
\text { do material seco }\end{array}$ \\
\hline Fluxo de ar de secagem & Tamanho de partícula do material seco \\
\hline Tempo de residência do material no equipamento & Umidade residual do extrato seco \\
\hline Porcentagem de aspiração & $\begin{array}{l}\text { Controla a formação das partículas e o tamanho do material seco. } \\
\text { Precisa se manter constante durante todo o processo. }\end{array}$ \\
\hline \multicolumn{2}{|c|}{ Relacionados ao Equipamento } \\
\hline Tipo do equipamento & Determina eficiência e tempo de processo \\
\hline $\begin{array}{l}\text { Processo de atomização do líquido } \\
\text { (bico pressurizado, disco rotativo) }\end{array}$ & Estrutura física do material seco, escala de fabricação. \\
\hline Diâmetro do bico atomizador & Tamanho de partícula do material seco \\
\hline Filtro de saída do ar de exaustão & Pressão interna do sistema, rendimento do processo. \\
\hline \multicolumn{2}{|c|}{ Relacionados à Formulação } \\
\hline Concentração de sólidos totais & Quantidade de material recuperado \\
\hline Viscosidade do extrato fluido & Fluxo de bombeamento, entupimento do sistema \\
\hline Densidade do agente de secagem & Fluxo de bombeamento, entupimento do sistema \\
\hline Veículo do extrato fluido (aquoso, orgânico) & $\begin{array}{l}\text { Tipo de sistema de uso de equipamento (fechado ou aberto), } \\
\text { temperatura de entrada do líquido, estrutura física e tamanho de } \\
\text { partícula do material seco }\end{array}$ \\
\hline Tensão superficial & Tamanho de partícula do material seco \\
\hline
\end{tabular}


Figura 2. Requisitos necessários para se viabilizar a execução do estudo de estabilidade de um insumo farmacêutico ativo (IFA) de origem vegetal padronizado obtido por spray-drying.

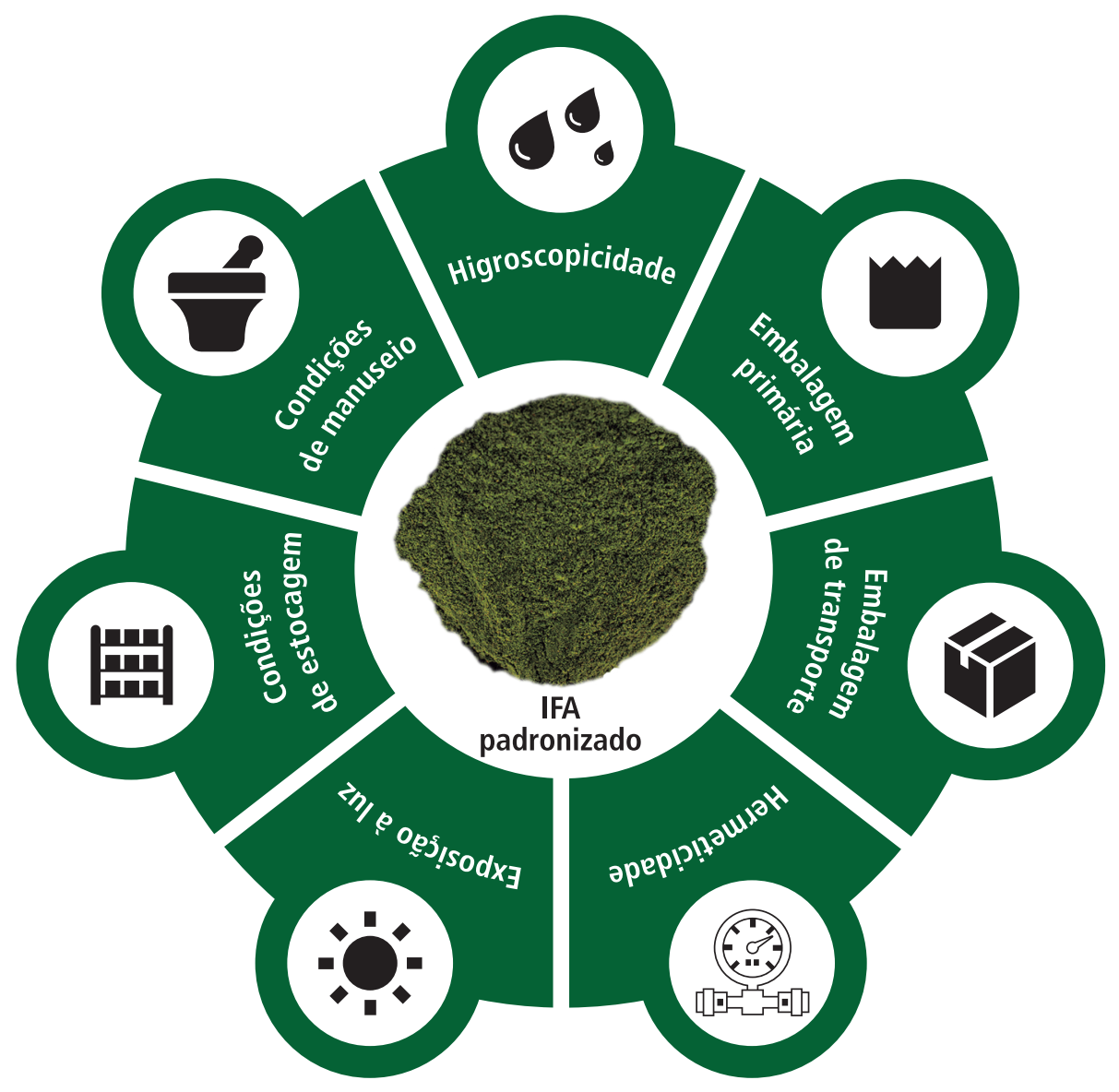

A Figura 2 apresenta os pré-requisitos a serem avaliados antes de submeter o IFA de origem vegetal a um estudo de estabilidade. As metodologias analíticas abordadas são variáveis, sendo a cromatografia líquida a mais empregada para o acompanhamento desses estudos. Neste trabalho, é recomendada a realização dos estudos de estabilidade nas condições de estocagem estabelecidas pela legislação vigente, adaptadas da Resolução da Diretoria Colegiada (RDC) 318/2019, da Anvisa, nos quais são realizados ensaios para atestar o tempo de prateleira de IFA de origem sintética em condições ambiente de estocagem (15), bem como estudos de fotoestabilidade quando necessário, segundo recomendações da Anvisa.

As condições climáticas para a realização dos estudos de estabilidade de longa duração são $30{ }^{\circ} \mathrm{C}$ $\pm 2{ }^{\circ} \mathrm{C} / 75 \%$ UR $\pm 5 \%$ UR com amostragem nos períodos de 0 (zero), 3 (três) e 6 (seis), 9 (nove), 12 (doze), 18 (dezoito) e 24 (vinte e quatro) meses. As condições climáticas para a realização dos estudos de estabilidade acelerada são $40{ }^{\circ} \mathrm{C} \pm 2{ }^{\circ} \mathrm{C} / 75 \%$ $\mathrm{UR} \pm 5 \%$ UR com amostragem nos períodos de 0 (zero), 3 (três) e 6 (seis) meses (15). Esses estudos devem ser realizados em câmara climática devidamente qualificada, que corresponde a outro gargalo tecnológico, já que poucos laboratórios de pesquisa possuem esses equipamentos de acordo com as boas práticas de laboratório.

Os estudos de estabilidade preliminares, em escala laboratorial, devem ser conduzidos de forma miniaturizada, com o produto em embalagem primária e quando possível também na secundária que muitas vezes já é a própria embalagem de transporte, com descrições idênticas, em termos de especificações técnicas, daquelas a serem comercializadas no futuro. Esses ensaios são importantes, pois muitos extratos são higroscópicos, e seus metabólitos termo e fotolábeis. 
Segundo resultados reportados por Cortés-Rojas e cols. (2016), o material de embalagem, frente a determinadas condições de estocagem, apresenta grande impacto na estabilidade de composições fitofarmacêuticas (35).

Além dos critérios de embalagem como proteção contra a luz, e para aumentar a segurança do uso e a validade desses produtos, variações na avaliação desses estudos devem ser conduzidas, como por exemplo, quanto a necessidade ou não de vácuo, visando o aspecto de hermeticidade do produto.

Assim, os estudos de estabilidade podem ser realizados aliados a diferentes materiais de acondicionamento, como em embalagens plásticas e/ou aluminizadas, na presença ou ausência de ar (sistemas sob vácuo), dependendo das necessidades específicas de cada produto e sua forma de manuseio.

A estabilidade do IFA de origem vegetal deve ser atestada por métodos analíticos quantitativos validados, capazes de detectar, ao longo do tempo, mudanças nas propriedades físicas, químicas ou microbiológicas do IFA. Além disso, as metodologias aplicadas devem ser capazes de mensurar com exatidão o teor do insumo farmacêutico ativo, produtos de degradação, quando aplicável e outros componentes de interesse, sem interferência (15), sabendo que, ao final do estudo de estabilidade, a variação máxima permitida para o teor de marcadores ativos será de no máximo $10 \%$ do valor de liberação do lote (5).

Além de todas as necessidades técnicas mencionadas, e em função da garantia da qualidade, todas as etapas devem ser devidamente documentadas em formulários próprios da empresa, a fim de manter a rastreabilidade do processo de acordo com a RDC 26/2014 (21). As amostras devem ser devidamente codificadas mantendo os registros de todos os experimentos executados, de preferência de forma ordenada cronologicamente.

\section{CONCLUSÃO}

A técnica de Brainstorming reuniu expertises e ampliou as discussões sobre os processos envolvidos na preparação de IFA de origem vegetal padronizados. A combinação dessa metodologia com a construção do diagrama de causa e efeito e os pontos relativos à estabilidade, possibilitou a avaliação de vários aspectos que influenciam a qualidade do produto final. Ademais, a discussão aprofundada, de ordem teórica e prática de aspectos críticos na cadeia de produção desses IFA, contribui para a área de pesquisa e desenvolvimento em produtos naturais. $\mathrm{O}$ assunto exposto inspira o estreitamento da distância entre a academia e a indústria, o que pode diminuir o tempo de desenvolvimento de um produto bem como assegurar a qualidade, segurança e eficácia destes medicamentos. A identificação de parâmetros críticos de processo na concepção de novos medicamentos pode servir como uma ferramenta para a inovação na área de tecnologia de fitoterápicos.

\section{AGRADECIMENTOS}

Ao Sr. Luiz Augusto Kelly, pelo auxílio nas atividades laboratoriais, ao Sr. Luciano Simões Pereira pela edição das imagens e à equipe de produtos naturais da Vice-Diretoria de Educação, Pesquisa e Inovação (VDEPI) de Farmanguinhos, Fiocruz.

\section{REFERENNCIAS}

1. Oliveira OW, Petrovick PR. Secagem por aspersão (spray drying) de extratos vegetais: bases e aplicações. Rev Bras Farmacog. 2010;20(4):641-650.

2. Souza CRF. Estudo comparativo da produção de extrato seco de Bauhinia fortificata Link pelos processos de spray-dryer e leito de jorro. [Dissertação]. Ribeirão Preto: Faculdade de Ciências Farmacêuticas de Ribeirão Preto, Universidade de São Paulo. 2003.
3. Daza LD, Fujita A, Fávaro-Trindade CS, Rodrigues-Ract JN, Granato D, Genovese MI. Effect of spray drying conditions on the physical properties of Cagaita (Eugenia dysenterica DC.) fruit extracts. Food Bioprod Process. 2016;97:20-29._DOI: 10.1016/j.fbp.2015.10.001.

4. BRASIL. Resolução RDC N $\mathrm{N}^{\mathrm{2}} 235$, de 20 de junho de 2018. Dispõe sobre alterações e inclusões de controle de qualidade no registro e pós-registro de medicamentos 
dinamizados, fitoterápicos, específicos e produtos biológicos. Brasília: Agência Nacional de Vigilância Sanitária. Diário Oficial da União, $n^{\circ} 120,25$ de junho de 2018. Seção 1. p. 35.

5. BRASIL. Instrução Normativa 04/2014 de 18 de junho de 2014. Determina a publicação do Guia de orientação para registro de Medicamento Fitoterápico e registro e notificação de Produto Tradicional Fitoterápico. Brasília: Agência Nacional de Vigilância Sanitária. Diário Oficial da União, no 116, 20 de junho de 2014. Seção 1. p. 86.

6. ICH. Harmonised Tripartite Guideline. Pharmaceutical Development Q8(R2). Agosto 2009. International Conference on Harmonisation of Technical Requirements for Registration of Pharmaceuticals for Human Use. Disponível em: https://database.ich.org/sites/default/ files/Q8_R2_Guideline.pdf. Acesso em: 01 maio 2020.

7. Costa TM. Identificação dos parâmetros críticos de processo relacionados à velocidade de dissolução de comprimidos de ibuprofeno por abordagem Quality by Design. [Dissertação]. Rio de Janeiro: Instituto de Tecnologia em Fármacos - Farmanguinhos, Fundação Oswaldo Cruz (FIOCRUZ). 2016.

8. BRASIL. Farmacopeia Brasileira. $6^{\mathrm{a}}$ ed. Volume 1. Brasília: Agência Nacional de Vigilância Sanitária. 2019. Disponível em: http://portal.anvisa.gov.br/documents/ 33832/259143/Volume+I+Pronto.pdf/4ff0dfe8-8a1d46b9-84f7-7fa9673elee1. Acesso em: 01 maio 2020.

9. BRASIL. Consolidado de normas de registro e notificação de fitoterápicos, de 26 de outubro de 2018. Brasília: Agência Nacional de Vigilância Sanitária. 2018. Disponível em: http://portal.anvisa.gov.br/ documents/33836/2501251/Consolidado_fitoterapicos 2018.pdf/a2f53581-43e5-47bb-8731-99d739114e10. Acesso em: 01 maio 2020.

10. BRASIL. Instrução Normativa $\mathrm{N}^{\circ} 39$, de 21 de agosto de 2019. Dispõe sobre as Boas Práticas de Fabricação complementares a Medicamentos Fitoterápicos. Brasília: Agência Nacional de Vigilância Sanitária. 2019. Diário Oficial da União $n^{\circ} 162,22$ de agosto de 2019. Seção 1. p. 87-88.

11. BRASIL. RDC No 69, de 08 de dezembro de 2014. Dispõe sobre as Boas Práticas de Fabricação de Insumos Farmacêuticos Ativos. Brasília: Agência Nacional de Vigilância Sanitária. Diário Oficial da União nº 238, 09 de dezembro de 2014. Seção 1. p. 43-52.

12. Alves FNR. Desafio para Inovação em Fitomedicamentos no Contexto da Indústria Farmacêutica Nacional. Rev Fitos. 2005;1(1):18-29.

13. Kunle OF; Egharevba HO; Ahmadu PO. Standardization of herbal medicines - A review. Int J Biodivers Conserv. 2012;4(3):101-112. DOI: 10.5897/IJBC11.163.
14. Li Y; Shen Y; Yao CL; Guo DA. Quality assessment of herbal medicines based on chemical fingerprints combined with chemometrics approach: a review. J Pharm Biomed Anal. 2020;185:113215. DOI: 10.1016/j. jpba.2020.113215.

15. BRASIL. RDC No 318, de 6 de novembro de 2019. Estabelece os critérios para a realização dos Estudos de Estabilidade de insumos farmacêuticos ativos e medicamentos, exceto biológicos e dá outras providências. Brasília: Agência Nacional de Vigilância Sanitária. Diário Oficial da União no 216, 07 de novembro de 2019. Seção 1. p. 97 - 101.

16. Zainol AS; Yusof WZM; Mastor KA; Sanusi ZM; Ramli NM. Using group brainstorming in industrial design context: factors inhibit and exhibit. Procedia Soc Behav Sci. 2012;49:106-119. DOI: 10.1016/j.sbspro. 2012.07.010.

17. Holanda MA; Pinto ACBRF. Utilização do diagrama de Ishikawa e brainstorming para solução do problema de assertividade de estoque em uma indústria da região metropolitana de recife. In: XXIX Encontro Nacional de Engenharia de Produção. 2009. Salvador: Associação Brasileira de Engenharia de Produção; 2009.

18. Honda MM. Melhoria de processos através do delineamento de experimentos aplicado a uma indústria de cosméticos. [Monografia]. São Paulo: Escola Politécnica da Universidade de São Paulo; Universidade de São Paulo. 2007.

19. Souza AP; Duarte NR; Carvalho ED; Melo ACS; Martins VWB. Ferramentas da qualidade aplicadas à melhoria de Operações Logísticas: Um Estudo Orientado a Farmácias de Manipulação. In: XXII Simpósio de Engenharia de Produção. 2015. Bauru: Faculdade de Engenharia de Bauru (UNESP); 2015.

20. BRASIL. RDC N $\mathrm{N}^{\mathrm{0}}$ 57; de 17 de novembro de 2009. Dispõe sobre o registro de insumos farmacêuticos ativos (IFA) e dá outras providências. Brasília: Agência Nacional de Vigilância Sanitária. Diário Oficial da União $n^{\circ} 220 ; 18$ de novembro de 2009. Seção 1. p. 39-40.

21. BRASIL. RDC No 26; de 13 de maio de 2014. Dispõe sobre o registro de medicamentos fitoterápicos e o registro e a notificação de produtos tradicionais fitoterápicos. Brasília: Agência Nacional de Vigilância Sanitária. Diário Oficial da União n ${ }^{\circ} 90 ; 14$ de maio de 2014. Seção 1. p. 52-58.

22. Borges DB; Farias MR; Simões CMO; Schenkel EP. Comparação das metodologias da Farmacopeia Brasileira para determinação de água em matériasprimas vegetais; e validação da determinação de água em analisador de umidade para Calendula officinalis L.; Foeniculum vulgare Miller; Maytenus ilicifolia Mart. ex. Reissek e Passiflora alata Curtis. Rev Bras Farmacogn. 2005;15(3):229-236. DOI: 10.1590/S0102$695 \times 2005000300013$. 
23. Chanda S. Importance of pharmacognostic study of medicinal plants: An overview. J Pharmacogn Phytochem. 2014;2(5): 69-73.

24. Souza CRF; Ramos DN; Cortes-Rojas DF; Oliveira WP. Stability testing and shelf live prediction of a spouted bed dried phytopharmaceutical preparation from Maytenus ilicifolia. Can J Chem Eng. 2013;91:1847-1855. DOI: 10.1002/cjce. 21887 .

25. Soriani RR. Irradiação de drogas vegetais: aspectos microbiológicos e químicos. [Dissertação]. São Paulo: Faculdade de Ciências Farmacêuticas; Universidade de São Paulo. 2004.

26. WHO. Guidelines for assessing quality of herbal medicines with reference to contaminants and residues. Genebra: Organização Mundial de Saúde. Disponível em: https://apps.who.int/iris/bitstream/handle/10665/ $43510 / 9789241594448$ eng.pdf? sequence $=1 \&$ is Allowed=y. Acesso em: 01 maio 2020.

27. Simões CMO; Schenkel EP; Gosmann G; Palazzo de Mello JC; Mentz LA; Petrovick PR. Farmacognosia da planta ao medicamento. $6^{\mathrm{a}}$ ed. Florianópolis: Editora da UFSC. 2007.

28. ICH. ICH Harmonised Tripartite Guideline. Impurities: Guideline for Residual Solvents Q3C (R6). Outubro 2016. International Conference on Harmonisation of Technical Requirements for Registration of Pharmaceuticals for Human Use. Disponível em: https:// database.ich.org/sites/default/files/Q3C-R6_Guideline ErrorCorrection_2019_0410_0.pdf. Acesso em: 01 maio 2020 .

29. Migliato KF; Corrêa MA; Salgado HRN; Tognolli JO; Sacramento LVS; Palazzo de Mello JC; Giannini MJSM; Almeida AMF; Pizzolitto AC. Planejamento experimental na otimização da extração dos frutos de Syzygium cumini (L.) Skeels. Quím Nova. 2011;34(4):695-699. DOI: $10.1590 / \mathrm{S} 0100-40422011000400024$

30. Soares PK. Planejamento quimiométrico para otimização do solvente extrator e análise exploratória da impressão digital cromatográfica de Erythrina speciosa Andrews. [Tese]. Campinas: Instituto de Química; Universidade Estadual de Campinas. 2010.

31. Wiegand; J. Falling-film evaporators and their applications in the food industry. J. Appl. Chem. Biotechnol. 1971;21:351-358.

32. Moreno FL; Hernández E; Raventós M; Robles C; Ruiz Y. A process to concentrate coffee extract by the integration of falling film and block freeze-concentration. J. Food Eng. 2014;128:88-95. DOI: 10.1016/j. jfoodeng.2013.12.022

33. Gourdon M; Mura E. Performance evaluation of falling film evaporators in the dairy industry food and bioproducts processing. Food Bioprod Process. 2017;101:22-31. DOI: 10.1016/j.fbp.2016.10.004
34. Souza AV; Fernandes JF; Trali JB; Galvão P; Pedro MAM. Aplicação da secagem por spray drying para a produção de extratos vegetais secos. Rev Cient Unilagos. 2013;1(1):181-193.

35. Cortez-Rojas DF; Souza CRF; Oliveira WP. Assessment of stability of spray dried extract from the medicinal plant Bidens pilosa L. J King Saud Univ Eng Sci. 2016;28(2):141-146. DOI: 10.1016/j.jksues.2014.04.004.

36. Souza CRF; Fernandes LP; Bott RF; Oliveira WP. Influência do processo de secagem e condição de armazenamento de extratos secos de Bauhinia forficata e Passiflora alata sobre seu perfil de dissolução. Rev Bras Plantas Med. 2015;17(1):67-75. DOI: 10.1590/1983084X/11_137.

37. Tonon RV; Brabet $\mathrm{C}$; Hubinger MD. Influence of process conditions on physicochemical properties of açaí (Euterpe oleraceae Mart.) powder produced by spray drying. J Food Eng. 2008;88:411-418. DOI: 10.1016/j. jfoodeng.2008.02.029.

38. Rowe RC; Sheskey PJ; Quinn ME. Handbook of Pharmaceutical Excipients. $6^{\mathrm{a}}$ ed. Londres: Pharmaceutical Press. 2009.

39. Patel BB; Patel JK; Chakraborty S; Shukla D. Revealing fact behind spray dried solid dispersion technology used for solubility enhancement. Saudi Pharm J. 2015; 23:352-365. DOI: 10.1016/j.jsps.2013.12.013.

40. Sosnik A; Seremeta KP. Advantages and challenges of spray-drying technology for the production of pure drug particles and drug-loaded polymeric carries. Adv Colloid Interface Sci. 2015;223:40-54. DOI: 10.1016/ j.cis.2015.05.003

41. Poozesh S; Bilgili E. Scale-up of pharmaceutical spray drying using scale-up rules: a review. Int J Pharm. 2019;562:271-292. DOI: 10.1016/j.ipharm.2019.03.047

42. Acosta-Esquijarosa J; Jáuregui-Haza U; AmaroGonzaléz D; Sordo-Martínez L. Spray drying of aqueous extract of Mangifera indica L (Vimang): Scale up for the process. World App Sci J. 2009;6(3):408-412.

43. Couto RO. Obtenção e caracterização do extrato seco padronizado da Rosmarinus officinalis L. (Lamiaceae). [Dissertação]. Goiânia: Faculdade de Farmácia; Universidade Federal de Goiás. 2011.

44. Souza GHB; Mello JCP; Lopes NP. Farmacognosia: Coletânea científica. $1^{\mathrm{a}}$ ed. Ouro Preto; UFOP. 2011.

45. Ferrari CC; Ribeiro CP; Aguirre JM. Secagem por atomização de polpa de amora-preta usando maltodextrina como agente secante. Braz J Food Technol. 2012;15(12):157-165. DOI: $10.1590 / \mathrm{S} 1981-$ 67232012005000009 . 